\title{
MULTIZONAL PROPORTIONAL INTEGRAL SPEED CONTROLLER FOR A DC MOTOR FED BY CUK CONVERTER
}

*Prof. Dr. Fahim Ahmed Khalifa, ** Prof. Dr. S. S. Shokralla, *** Eng. Ibrahim Shoaib Ibrahim

*Professor of Electrical Machines, Electrical Engineering Department, Faculty of Engineering, Suez Canal University, Egypt.

** Professor of control of Electrical Machines, Electrical Engineering Department, Faculty of Engineering, Menoufiya University, Egypt.

***Lecturer in Electrical Engineering Department, Alexandria Technical College, Higher Education

\begin{abstract}
In this paper a multizonal proportional integral (P I) speed controller for a closed loop speed control of a separately exited dc motor is presented. The motor is fed from a dc power supply and a Cuk converter. Step - up and step - down characteristics of the output voltage can be obtained. A high performance is achieved with a simple control circuit having only one switch (MOSFET) for the proposed system. The output voltage and current are smooth and free of ripples. The converter operates in both open and closed loop speed control. A multizonal proportional integral speed controller is used to overcome the possibility of change in the system parameters. The proposed modeling and simulation of the proposed system are performed using differential equations, which describe the system behavior in the different operating conditions .The run up, transient and steady state are presented. Speed control using multizonal proportional integral speed controller is given to satisfy the best required response for the load disturbances Also, the motor speed can follow the desired reference speed smoothly in the different operating zones. The experimental results will be have ensured the proposed controller robustness, simple, and powerful control application capabilities. The experimental and simulation results of the system for both open and closed loop speed control are verified and a good correlation between them was found.

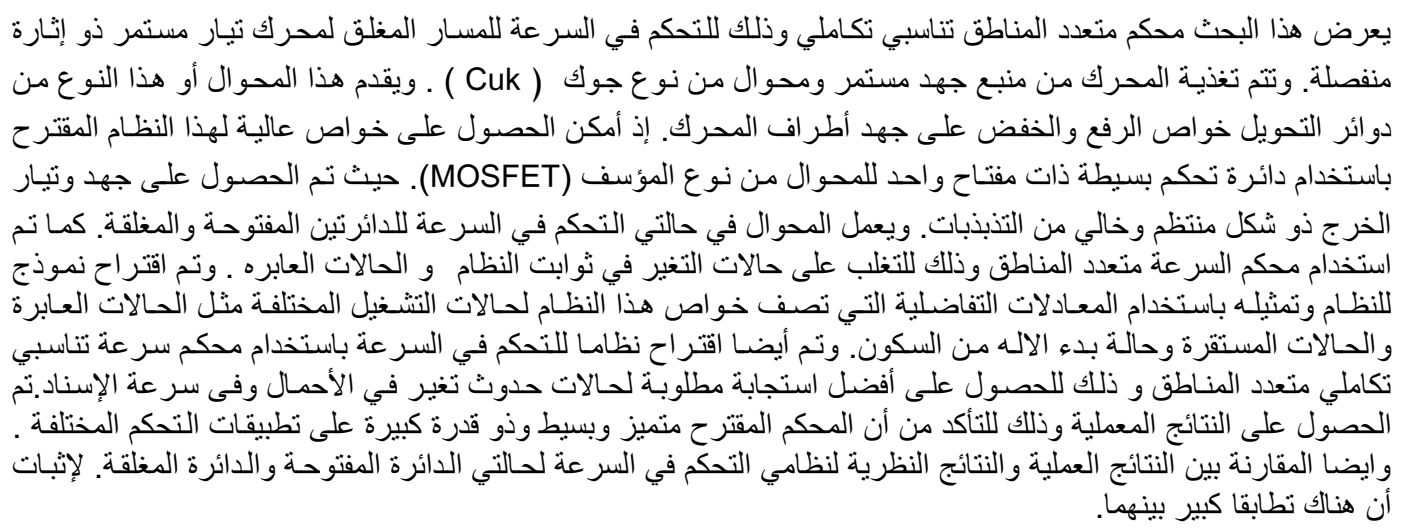

Ministry, Arab Republic of Egypt

KEYWORDS : Cuk converter, Multizonal proportional integral controller, separately excited DC motor. Speed control, AC to DC converter.

\section{1- INTRODUCTION}

The classical solution of Ac - Dc rectification using a full wave diode bridge followed by a bulk capacitor is being disconnected, due to it harmonics current content, which is rich in low order components. Direct current motor drives are used extensively in industries such as steel mill, paper mill, conveyors, and chemical industries. In many drive applications, the mechanical load varies 
considerably during operation. Such examples of this load are robots and machine tools. When a fixed controller setting is used for a DC drive system with wide load changes, unsatisfactory performance is often produced. The performance DC motor drives are important for multitude of industrial applications $\{1\}$. Precise, fast, effective Speed reference tracking with minimum overshoot/undershoot and small steady state error are essential control objectives. Conventional controllers are usually used for fixed structure, and fixed parameters design $\{2-5\}$. The tuning and optimization of these controllers are challenging and have difficult task, particularly under varying load conditions, and abnormal operation an artificial intelligent system based on fuzzy logic and neural network techniques was reported for a high performance DC drive (6). The simulation study for an intelligent rule-based error drive gain scheduling controller for a chopper fed DC series motor was proposed in $\{7\}$ Alternatively, an intelligent selfadaptive rule based speed regulator for a permanent magnet DC motor drive is implemented in $\{8\}$. The steady - state and dynamic performance of a symmetrical angle controlled DC motor is investigated, and the power factor of the system is improved using this technique. Also, the conventional analog proportional integral controller is used for speed control $\{9\}$. The power supplies can suffer considerably from current distortions and low power factor operations when a conventional diode bridge rectifier is operated with a DC filter capacitor at the output terminal. They result in large installation size and increased losses. To counteract these shortcomings, various passive and active input current wave shaping methods have been presented $\{3-10\}$. It is difficult to obtain sinusoidal supply currents with a near unity power factor for a wide variety of operating conditions. On the other hand, when the cascade combinations of a diode bridge and boost AC-DC converter are used as the rectifiers, the sinusoidal supply currents can then be actively wave shaped with a near unity power factor operation by filtering the high order current harmonics if the rectifiers are operated in discontinuous current conduction mode $\{7-11\}$. They also have the advantage of simple pulse width modulation (PWM) with uniform duty factor and a single power switching device which provides the necessary control over the currents both in single phase $\{11-12\}$. And three phase configurations $\{13\}$. Unfortunately, if both step-up and step-down output voltages, which have to be continuously regulated, are desired, they cannot satisfy the requirement. IF, for example, the rectifier converter system is considered, the rectifier with step-up and step-down characteristics will be useful because it enables the system to operate with pulse amplitude modulation at the converter input terminal. thus, PWM techniques for the converter circuit may be merely focused on the decreasing in input AC voltage harmonics. In the previous researches they haven't paid an attention for some different points of the operation with the load and speed reference changes. They have focused on one operating point only with proportional integral speed controller.

In this paper, a speed control for a separately excited DC motor fed from DC supply through a Cuk converter is presented. Step-up and step-down characteristics of the output voltage are obtained, the multizonal proportional integral speed controller is applied. The proposed modeling and digital simulation of the system is described in different modes of operation. An experimental system is built to verify the numerical simulation results. The comparison between the experimental and simulation results has proved a good agreement with each other. Both results give a prediction with a high motor speed performance over a wide range of reference speed and load changes.

\section{2- System Description}

The schematic diagram of the proposed system. Is shown in figure $\{1-\mathrm{a}\}$ the capacitor $\mathrm{C}$ acts as a transfer element. The inductance $L_{2}$ and capacitance Co are used as a filter to obtain DC output load voltage with minimum ripples . The switching frequency $\left(F_{S}\right)$ and the value of $\mathrm{C}$ are determined according to $L_{1}$ value. The resonance frequency is calculated from the equation

$F_{r}=\frac{1}{2 \pi} \sqrt{L_{1} C}$

and should be sufficiently higher than the switching frequency to prevent any resonance phenomenon in the AC circuit . The system parameters are given in the Appendix. Step-up and down behavior of the output voltage is obtained

by regulating the control voltage $\left(V_{C}\right)$ from zero to the maximum value of the carrier voltage ( $V_{\text {car }}$ ). The MOSFET is derived ON when the carrier voltage is lesser than or equal to the control voltage, which is the speed control output. The duty ratio is given:

\section{Duty ratio $=\frac{\mathrm{T}_{\mathrm{ON}}}{\mathrm{T}_{\mathrm{ON}}+\mathrm{T}_{\mathrm{OFF}}}$}

Where: Ton Is the Mosfet on time.

$$
\mathrm{T}_{\text {off }} \text { Is the Mosfet off time. }
$$

The parameter value of the designed system and motor are given in appendix (1) and (2). 


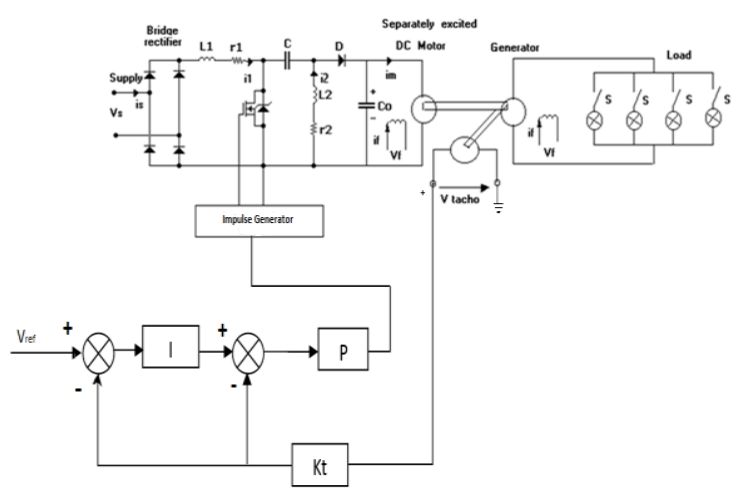

Figure (1-a) Schematic Diagram Of the proposed system
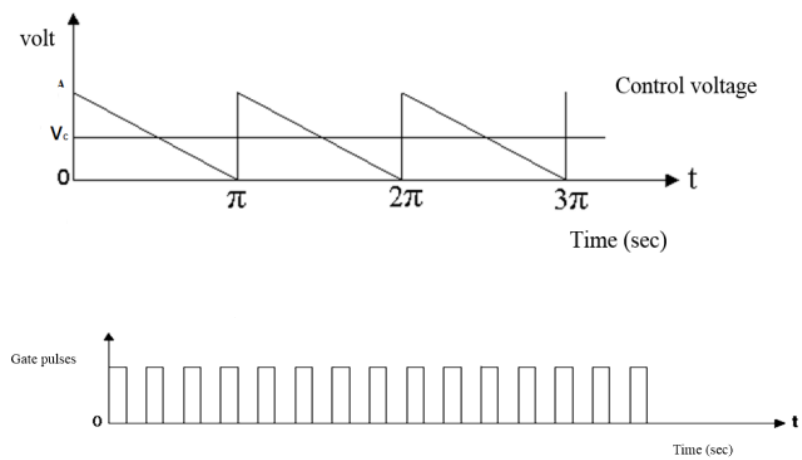

Figure (1-b) control voltage and output of control circuit

1- System modeling and simulation Mode (1) In this mode, the MOSFET is turned ON, the current $\boldsymbol{i}_{\mathbf{1}}$ will flow through the loop v- $\boldsymbol{L}_{\mathbf{1}}, \boldsymbol{r}_{\mathbf{1}}$. MOSFET. The capacitor $\mathrm{C}$ will discharge into the load circuit and the capacitor $\boldsymbol{C}_{\boldsymbol{o}}$. The differential equations describing this mode are written as follows:

$$
\frac{d i_{1}}{d t}=\frac{v-i_{1} r_{1}}{L_{1}}
$$

$$
\begin{aligned}
& \frac{d e}{d t}=-\frac{i_{2}}{C} \\
& \frac{\mathrm{d}_{m}}{\mathrm{dt}}=\left(V_{o}-R_{m} i_{m}-K_{m} \omega_{m}\right) / L_{m} \\
& \frac{d \omega_{m}}{d t}=\frac{K_{m} i_{m}-B \omega_{m}-T_{L}}{J} \\
& \frac{d V_{o}}{d t}=\frac{i_{2}-i_{m}}{C_{o}}
\end{aligned}
$$

$$
\frac{d i_{2}}{d t}=\frac{e-i_{2} r_{2}-V_{o}}{L_{2}}
$$

Mode (2)

In this mode, the MOSFET is still ON, the capacitor voltage (e) may fall to zero, and this depends on the current parameters and operating conditions. The current $\boldsymbol{i}_{\mathbf{2}}$ will flow through the diode $\mathrm{D}$.The differential equations describing this mode are written as follows:

$$
\begin{aligned}
& \frac{d i_{1}}{d t}=\frac{v-i_{1} r_{1}}{L_{1}} \\
& \frac{\mathrm{d} i_{m}}{\mathrm{dt}}=\left(V_{o}-R_{m} i_{m}-K_{m} \omega_{m}\right) / L_{m}
\end{aligned}
$$

$$
\frac{d i_{2}}{d t}=\frac{-i_{2} r_{2}-V_{o}}{L_{2}}
$$

Mode (3)

In this mode, the MOSFET is OFF, diode D is ON and the capacitor $\boldsymbol{C}_{\boldsymbol{o}}$ Charged, the corresponding differential equations in this mode are as follows:

$$
\begin{aligned}
& \frac{d i_{1}}{d t}=\frac{v-i_{1} r_{1}-e}{L_{1}} \\
& \frac{d e}{d t}=-\frac{i_{2}}{C} \\
& \frac{\mathrm{d} i_{m}}{\mathrm{dt}}=\left(V_{o}-R_{m} i_{m}-K_{m} \omega_{m}\right) / L_{m}
\end{aligned}
$$

$\frac{d \omega_{m}}{d t}=\frac{K_{m} i_{m}-B \omega_{m}-T_{L}}{J}$

$\frac{d V_{o}}{d t}=\frac{i_{2}-i_{m}}{C_{o}}$

$\frac{d i_{2}}{d t}=\frac{-i_{2} r_{2}-V_{o}}{L_{2}}$

\section{Mode (4)}

This mode occurs when the supply voltage is of quite small value and the supply current falls to zero. The differential equations describing this mode are written as follows:

$$
\frac{\mathrm{d} i_{m}}{\mathrm{dt}}=\left(\boldsymbol{V}_{o}-\boldsymbol{R}_{m} i_{m}-\boldsymbol{K}_{m} \boldsymbol{\omega}_{m}\right) / \boldsymbol{L}_{m}
$$




$$
\begin{aligned}
\frac{d \omega_{m}}{d t} & =\frac{K_{m} i_{m}-B \omega_{m}-T_{L}}{J} \\
\frac{d V_{o}}{d t} & =\frac{i_{2}-i_{m}}{C_{o}} \\
\frac{d i_{2}}{d t} & =\frac{-i_{2} r_{2}-V_{o}}{L_{2}}
\end{aligned}
$$

\section{4- SIMULATION AND EXPERMENTAL RESULTS}

I-Steady - State Performance Results

The relation between the duty ratio and the motor speed is shown in Figure (2) at different ratios from the light load to the full load (F.L). It is noticed that the speed is increased with the increasing of the control voltage.

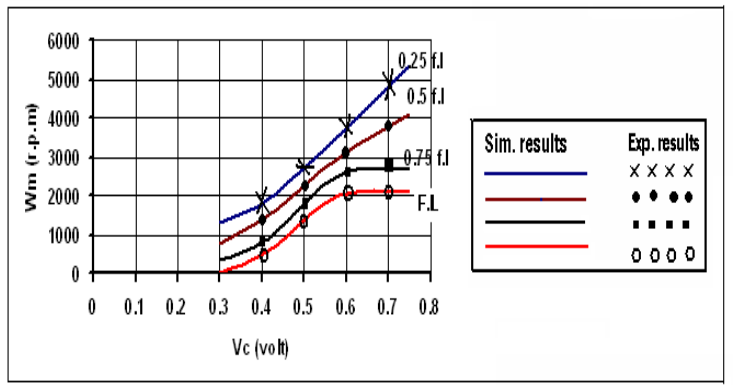

Figure (2) Simulation and experimental results for motor speed in (rpm.) versus control voltage

Figure (3) shows the relation between the duty ratio and the motor current. It is observed that the motor current value is constant with the increasing of the duty ratio. That is because the load torque value is constant during every ratio of the full load.

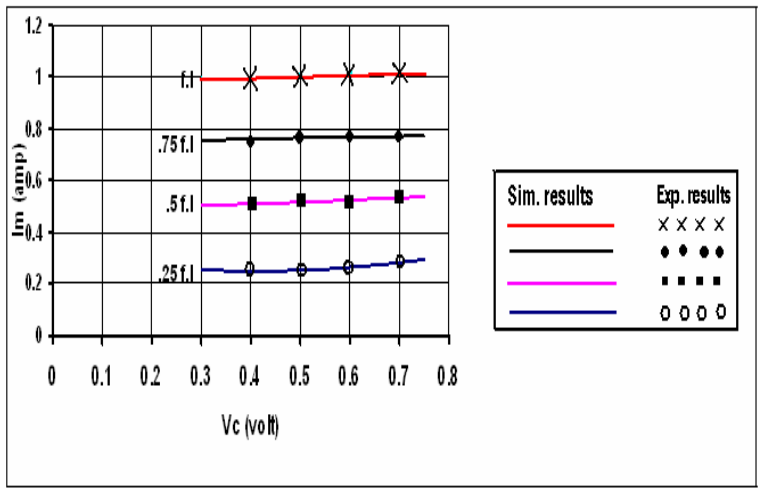

Figure (4) Simulation and experimental results for supply current versus control voltage

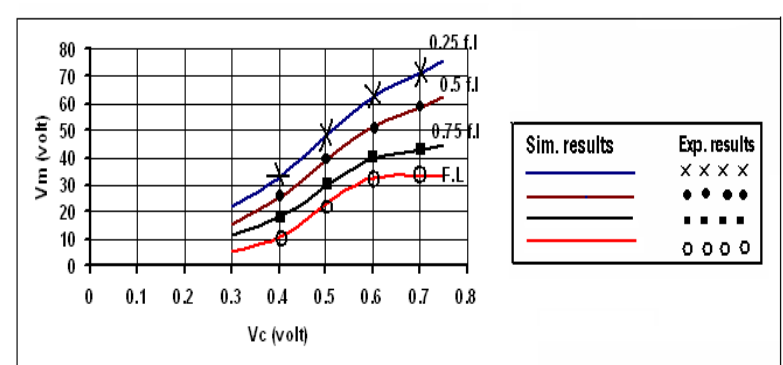

Figure (5) Simulation and experimental results for motor voltage versus control voltage

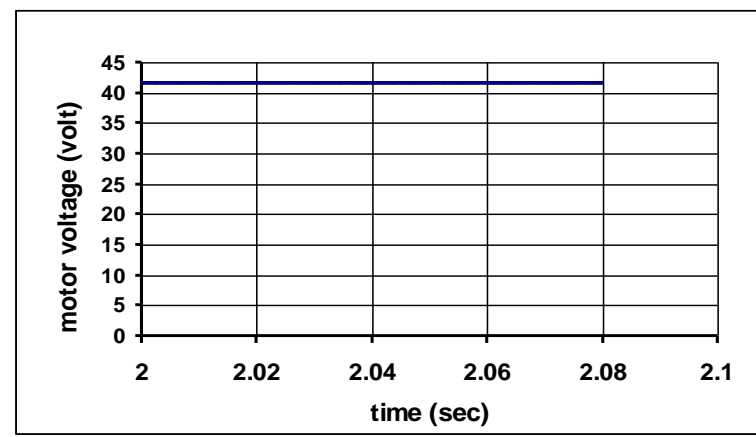

Figure (6-a) Simulation results for motor voltage during STEADY STATE

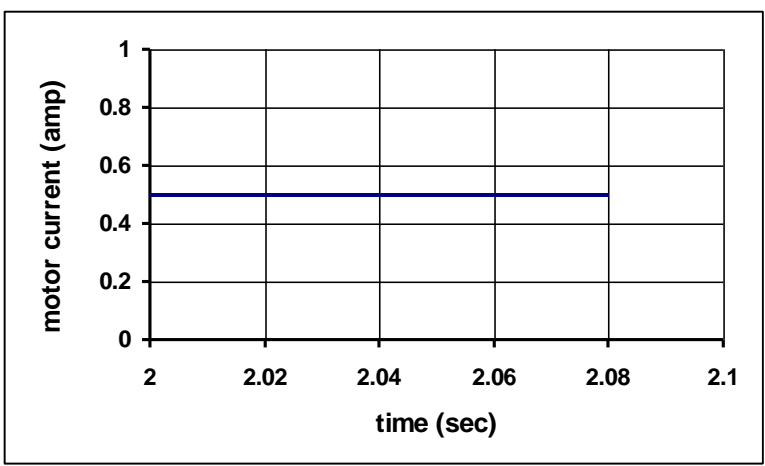

Figure (6-B) Simulation results for AC supply input current

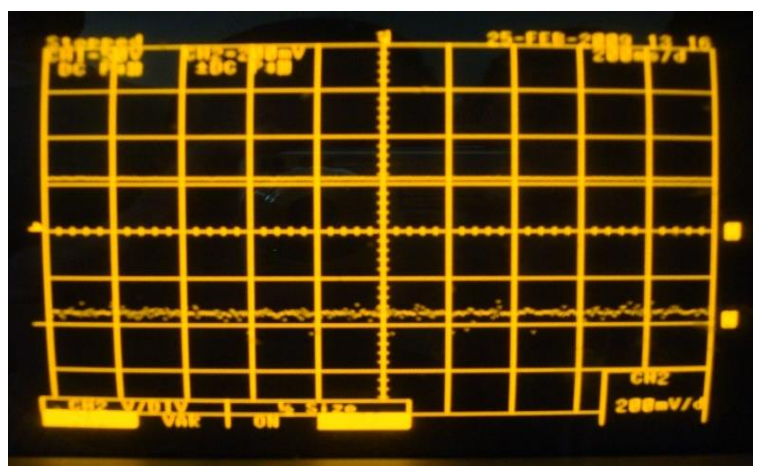

Figure (6-c) Experimental results for motor voltage and current 


\section{II-Steady - State waveforms Results}

This study is made at half full load torque $(0.065$ N.m) with a constant value of control Voltage (duty ratio) equals 0.5 the figures show the simulation and experimenters results for different Parameters. Figure (6) shows the simulation and experimental results for motor voltage and current respectively. It is observed that the motor voltage and motor current are constant and ripple free. Figure (7) shows the simulation and experimental results of variation of the source voltage and current under the same condition of operation with time, the simulation and experimental results clarify that the motor voltage, current and source voltage remain constant with time.

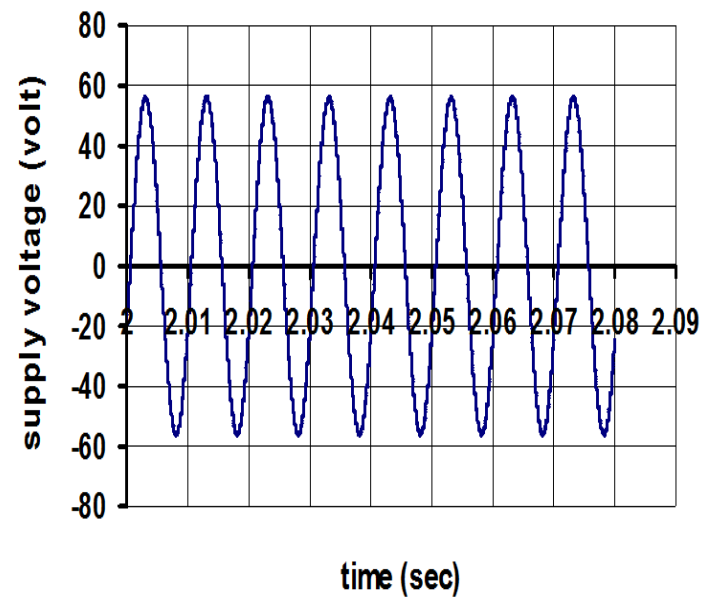

Figure (7-a) Simulatiom results for AC input voltage

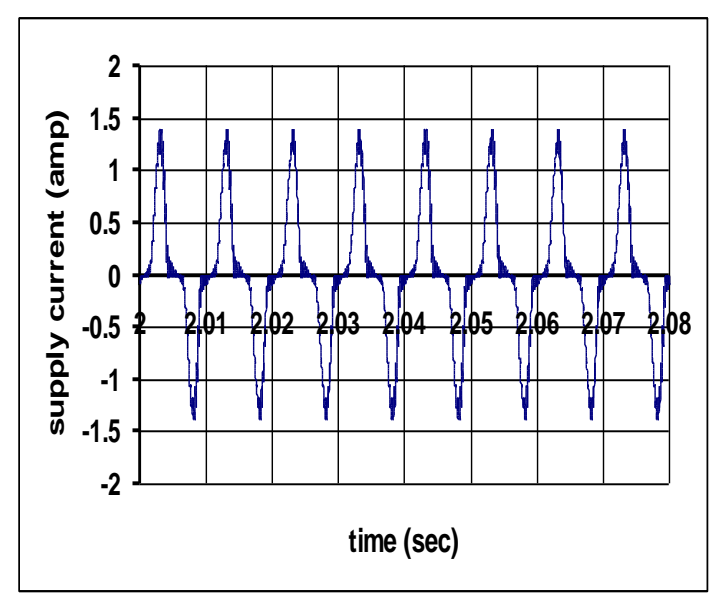

Figure (7 -B) Simulation results for AC supply input current

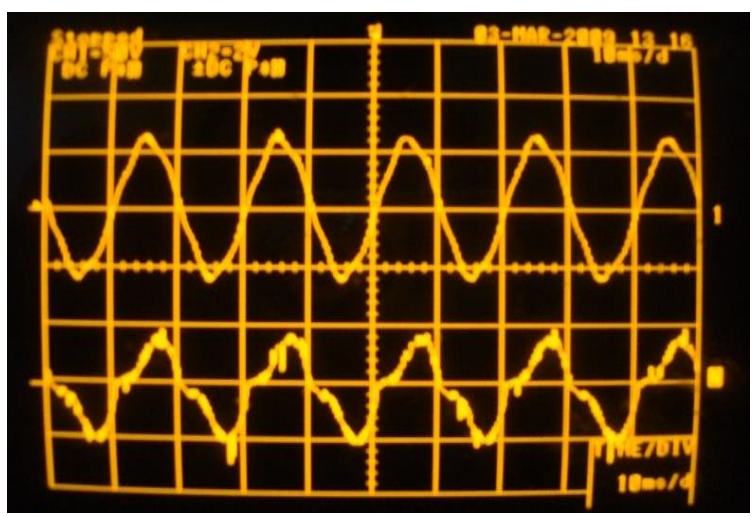

Figure (7 -c) Experimental results for AC supply input voltage and supply current during steady state

\section{III- Starting up Performance Results}

The results are taken and simulation for the same parameters under the starting up condition, at the half load and constant duty ratio 0.5 figure (8) shows the variation of the source voltage and current versus time. It is noticed that the current at starting has a large value then steady state. . Figure (9) shows the simulation and experimental results of the motor voltage and motor current during starting -up. It is noticed that the motor current at starting has a large value then steady-state.

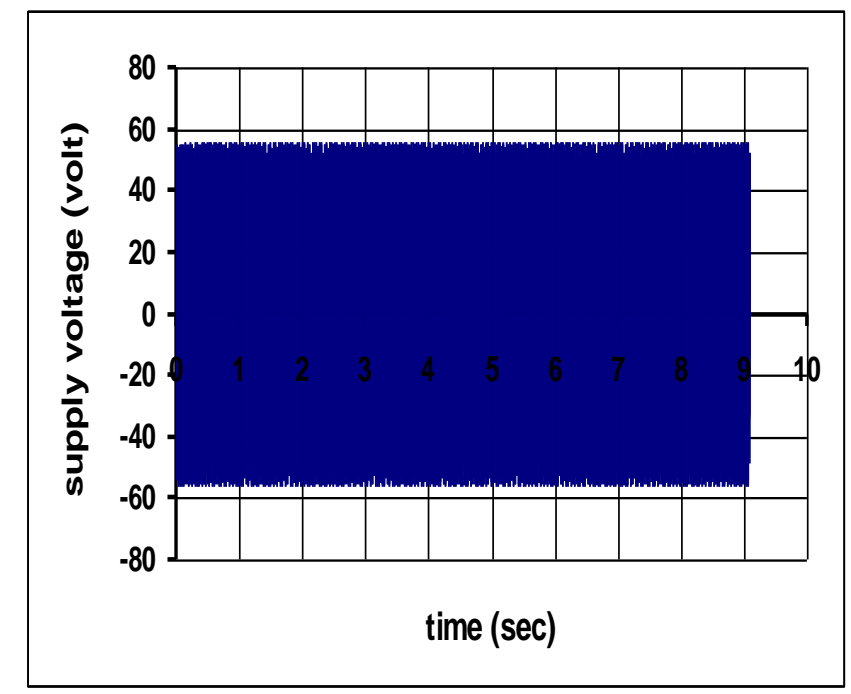

Figure (8-a) Simulation of AC supply input voltage during run-up 


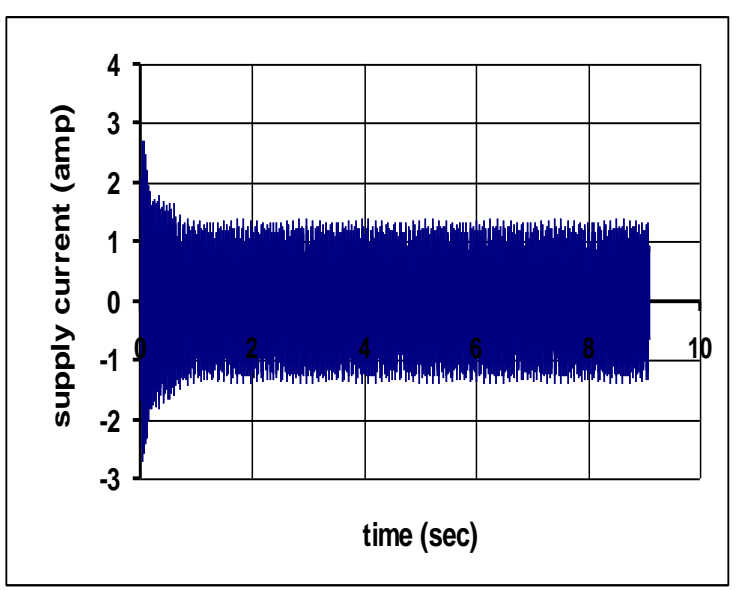

Figure (8-b) Simulation of AC supply input current during RUN-UP

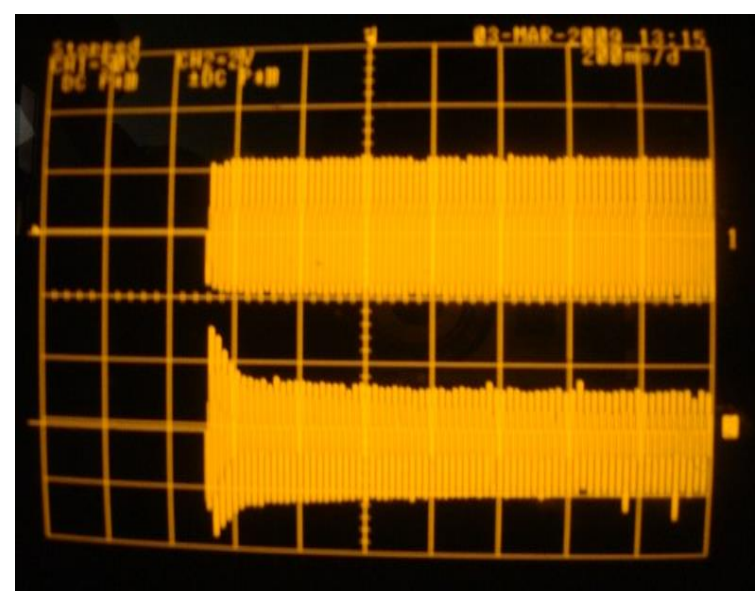

Figure (8-c) Experimental results for AC supply input voltage and current during RUN-UP

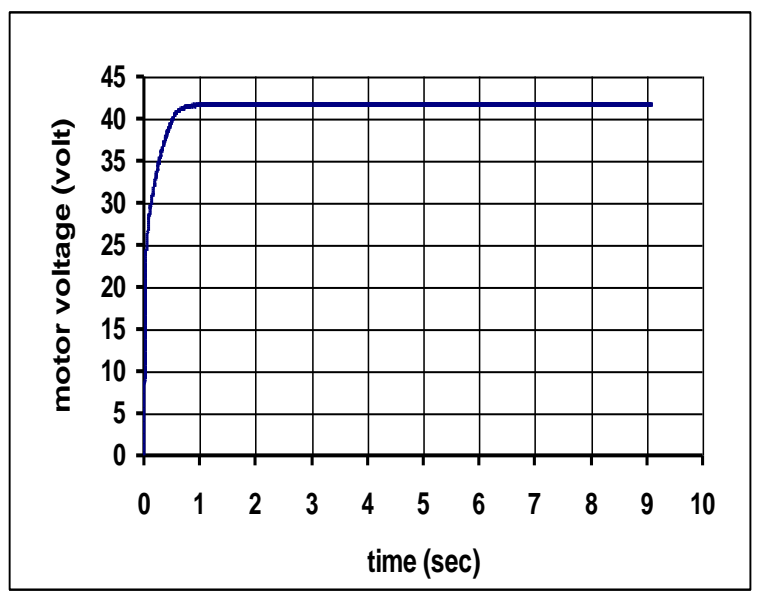

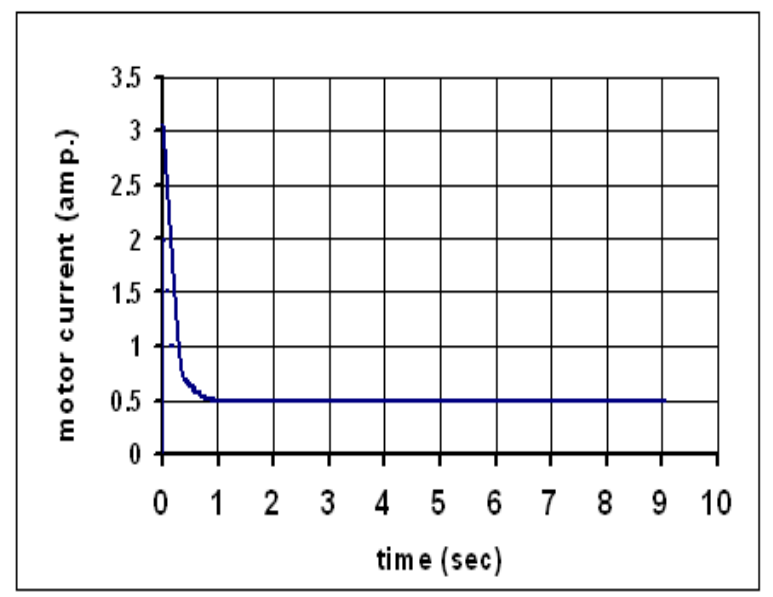

Figure (9-b) Simulation results for the motor current during RUN-UP.

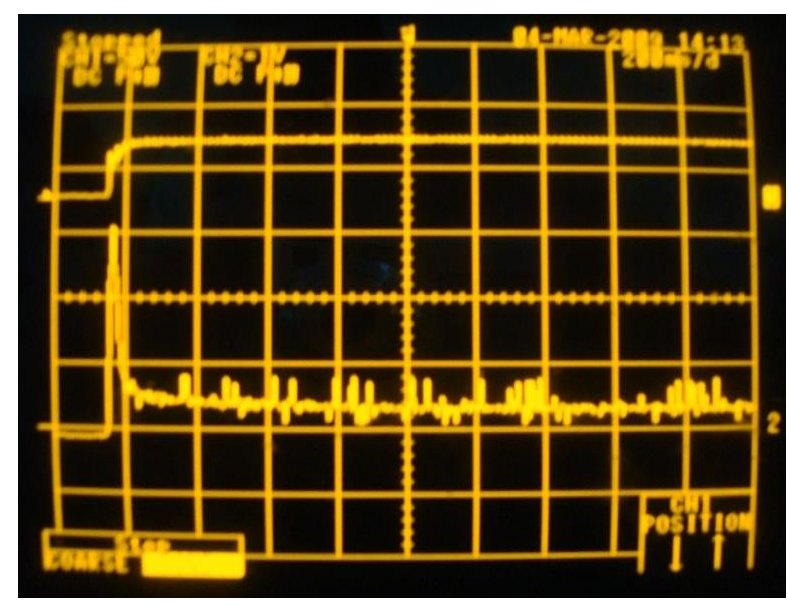

Figure (9-c) Experimental results for the motor voltage and current during RUN-UP

\section{Iv- Transient Performance Results}

Two kinds of changes have been proposed in order to study the characteristics of the system. The first change is a step change in the control voltage. The load is taken constant at the value of half full load. A positive step change from 0.25 to 0.35 volt in the duty ratio is taken. figures (10) shows the simulation and experimental result for the motor voltage due to step change in duty ratio from 0.25 to 0.35 .

Figure (9-a) Simulation results for the motor voltage during RUN-UP. 


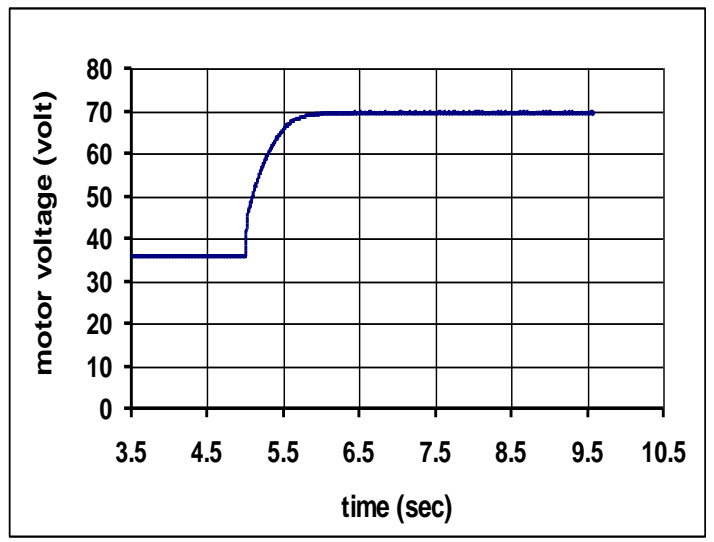

Figure (10-a) Variations of the motor input voltage due to change in Load torque from $(0.036$ : 0.06) .N.m

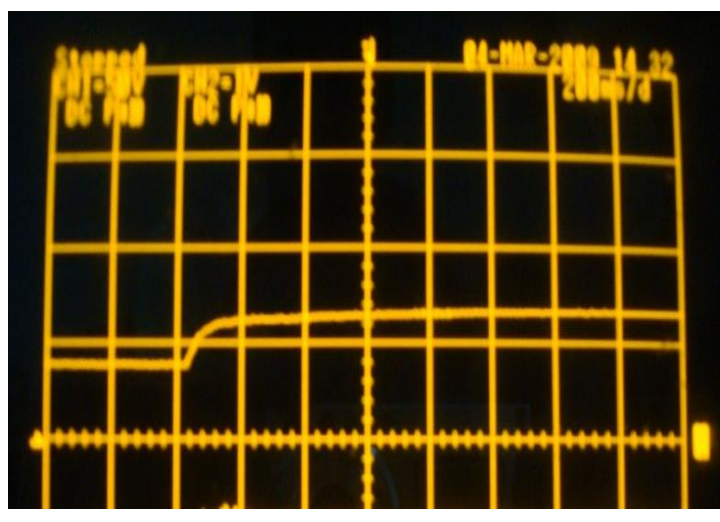

Figure (10-b) Variations of motor input voltage due to change in

load torque from $(0.036: 0.06)$.N.m.

Figure (11) shows the previous parameters due to negative step-change in duty ratio for 0.35 to 0.25 .

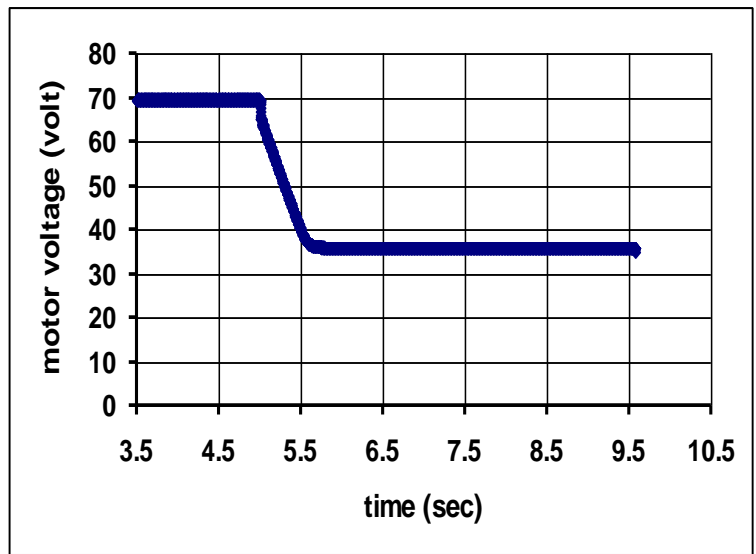

Figure (11-a) Variations of motor input voltage due to change in

Load torque from $(0.06: 0.036)$.N.m.

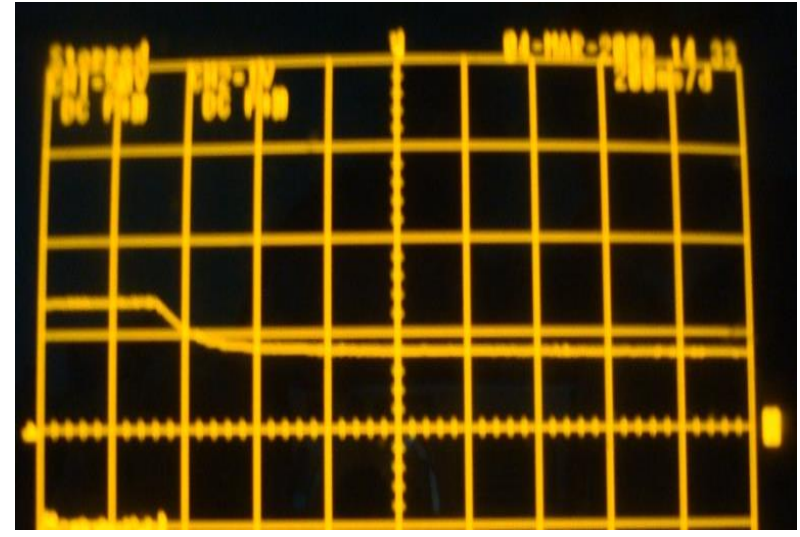

Figure (11-b) Variations of motor input voltage due to change in Load torque from (0.06: 0.036$)$ .N.m.

Figure (12) shows the simulation and experimental result for the motor voltage and current due to positive load step change from (0.036 to 0.06$)$ N.m. Figure (13) shows the same previous parameters due to a negative step change in the load from $(0.06$ to0.036) N.m.

Figure (14) shows the simulation and experimental result for the motor speed due to positive change in load torque from (0.036 to 0.06$)$ N.m.

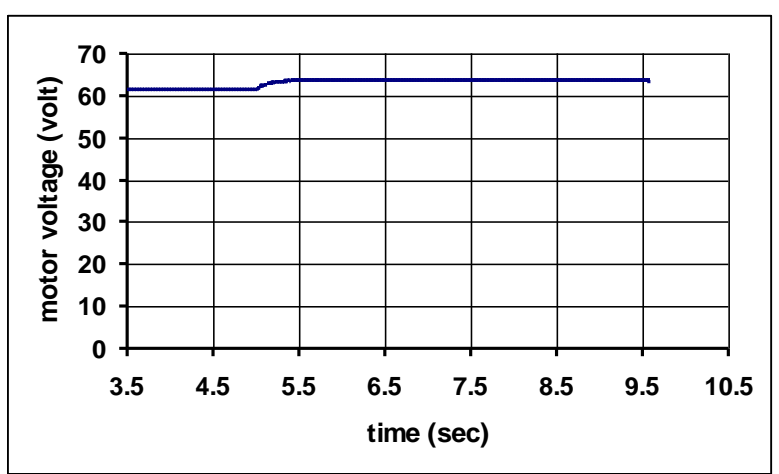

Figure (12-A) Variations of the motor input voltage due to change in load torque from $(0.36$ : 0.6) .N.m

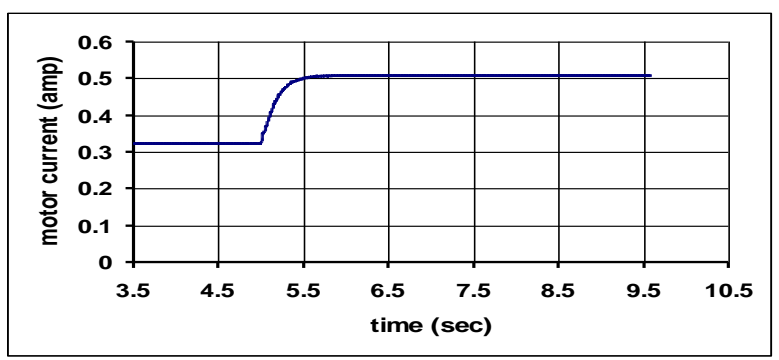

Figure (12-B) Variations of the motor input current due to change in load torque from $(0.36$ : 0.6) .N.m 


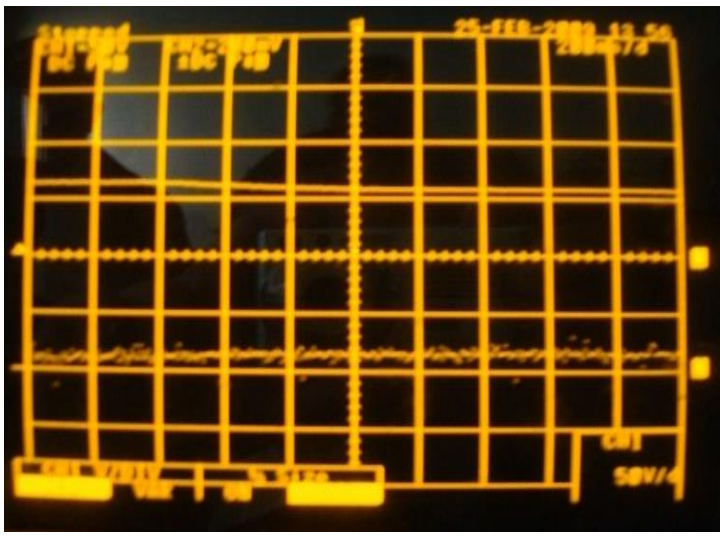

Figure (12-c) Experimental results of the motor input current due to change in load torque from (0.36 : 0.6) .N.m

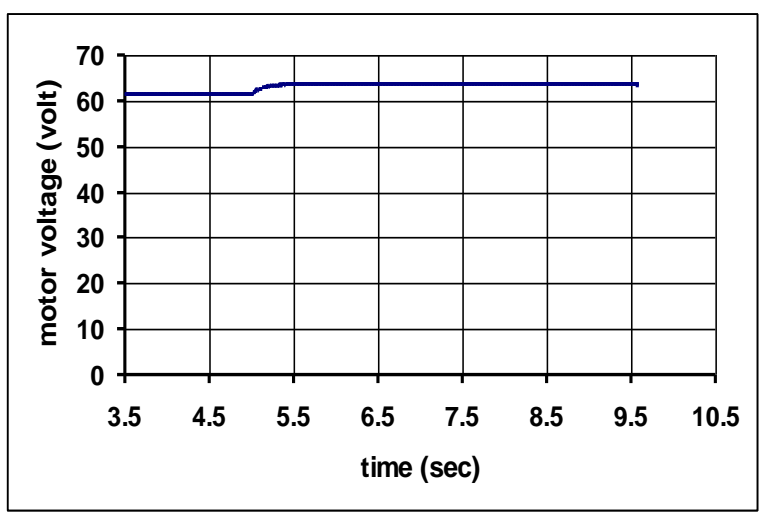

Figure (13-A) Variations of the motor input voltage due to change in load torque from $(0.6$ : 0.36) .N.m

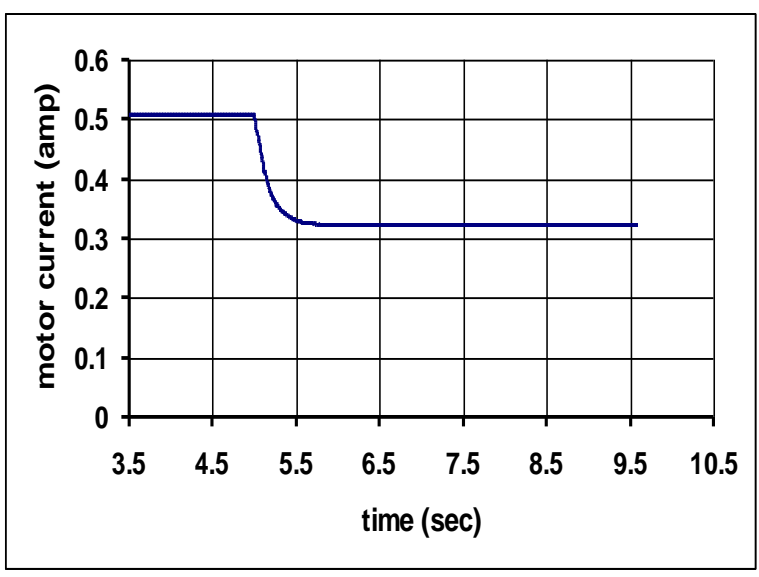

Figure (13-B) Variations of the motor input current due to change in load torque from $(0.6$ :

$$
\text { 0.36) .N.m }
$$

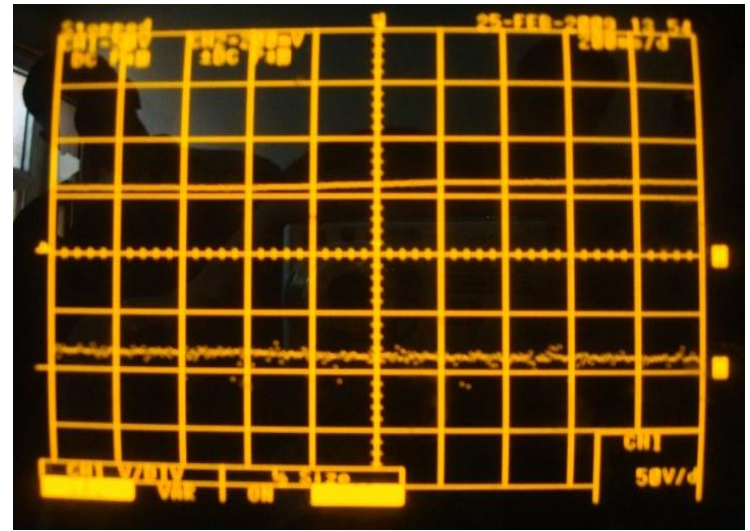

Figure (13-c) Variations of the motor input voltage and current due to change in load torque from $(0.6: 0.36)$ N.m.

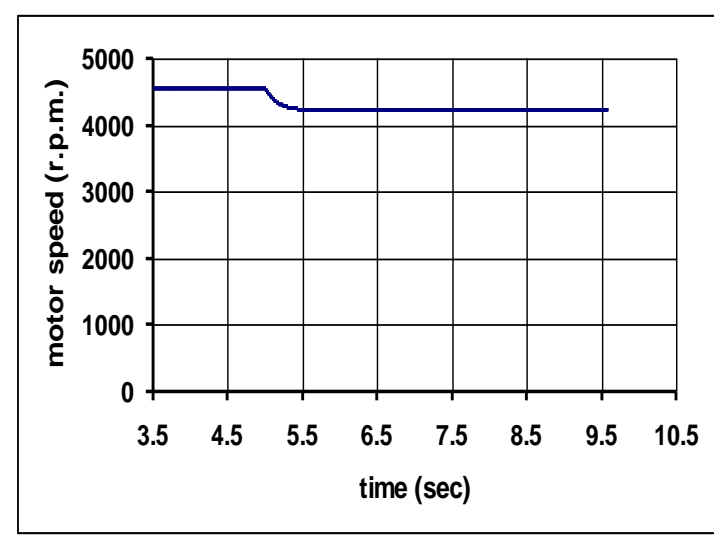

Figure (14-A) Variations of the motor speed due to change in load torque from $(0.36: 0.6)$.N.m

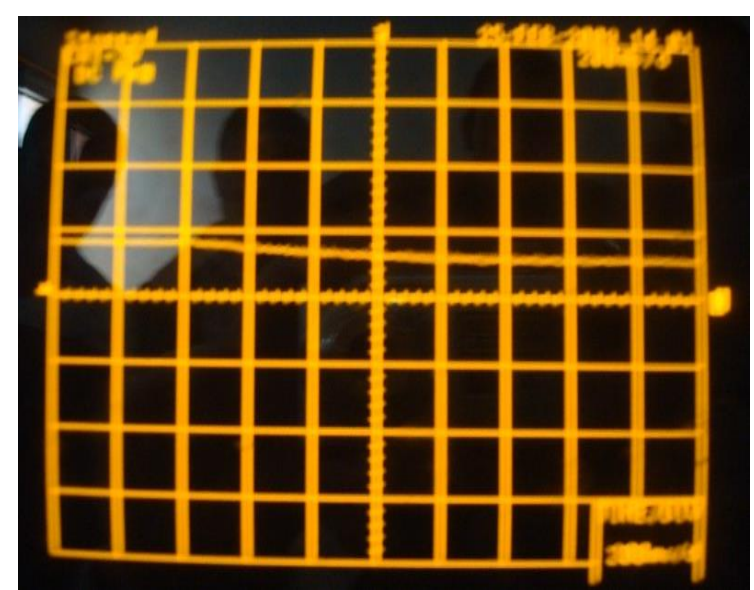

Figure (14-b) Variations of the motor speed due to change in load torque from $(0.36: 0.6)$.N.m 


\section{5- CLOSED LOOP SPEED CONTROL}

\section{I- System Transfer Function}

The open loop transfer function of the speed response with a step change in the control voltage for all the system is obtained and given as

$$
\mathbf{T} . \mathbf{F}=\frac{\mathrm{K}_{5}}{1+\mathrm{T}_{\mathrm{em}} \mathrm{s}}
$$

Figure (15) shown the complete block diagram for the closed loop system . A multizonal speed controller is designed to obtain wide range of the speed control using different proportional integral controllers for operating points. The load is divided into four zones. Zone one is from light load to 0.25 zone two from 0.25 to 0.5 of the full load. Zone three is from 0.5 to 0.75 of the full load. Zone four is from 0.75 to the full load. For any load, the PI speed controller is designed.

\section{II- Design of the PI speed Controller}

The open loop transfer function of the system is obtained according to figure (15) as follows :

$\frac{\omega_{m}(s)}{v_{r e f}(s)}=\left(\frac{K_{1} K_{s} K_{\tau}}{\tau_{1} s}\right)\left(\frac{1}{1+\tau_{e m} s}\right)$

In order that the system become stable the cross over frequency $\left(\omega_{c o}\right)$ for a phase margin more than $45^{\circ}$ is Found from the equation (24)

$\omega_{c o}=\frac{K_{1} K_{s} K_{t}}{\tau_{1} s}$

The parameters of the speed controller for the three zones are given in the Appendix.

\section{III- controller Equations}

The controller Equations are given as:

$$
\begin{aligned}
& \tau_{1}\left(\frac{d u}{d t}\right)=V_{r e f}-K_{1} \omega_{m} \\
& V_{c}=K_{1}\left(U-K_{t} \omega_{m}\right)
\end{aligned}
$$

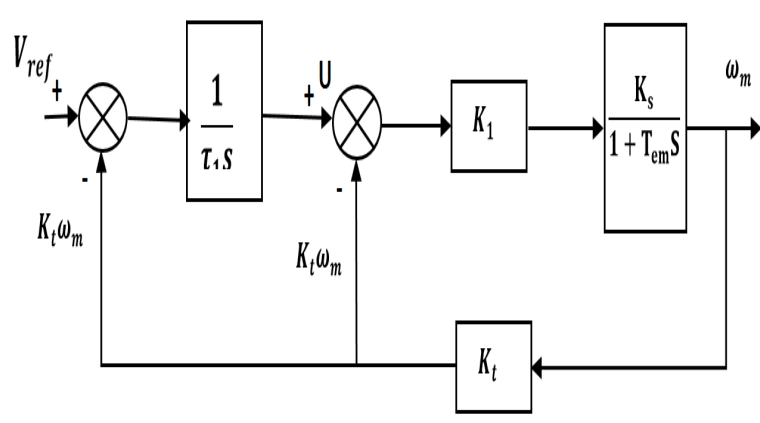

Figure (15) complete block diagram for closed loop control system

\section{IV-Closed loop Simulation and Experimental Results}

Zone two is taken as an example. Figure (16) shows the experimental and simulation result for the motor speed due to appositive load change from 0.5 to 0.75 from the full load, while figure (17) load change from 0.75 to 0.5 from the full load change and then returned with initial value . It is noticed that the speed is change and then returned to its initial value.

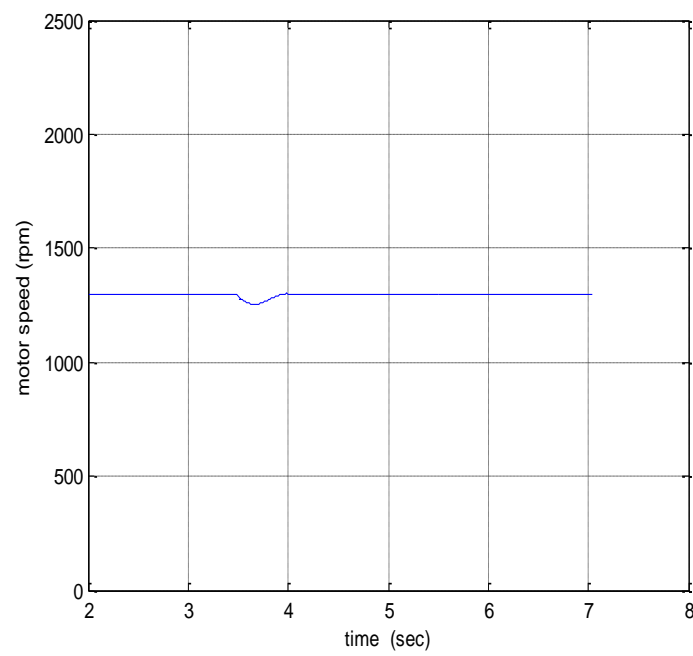

Figure (16-A) Simulation of motor speed in (rpm) due to negative change in load torque. 


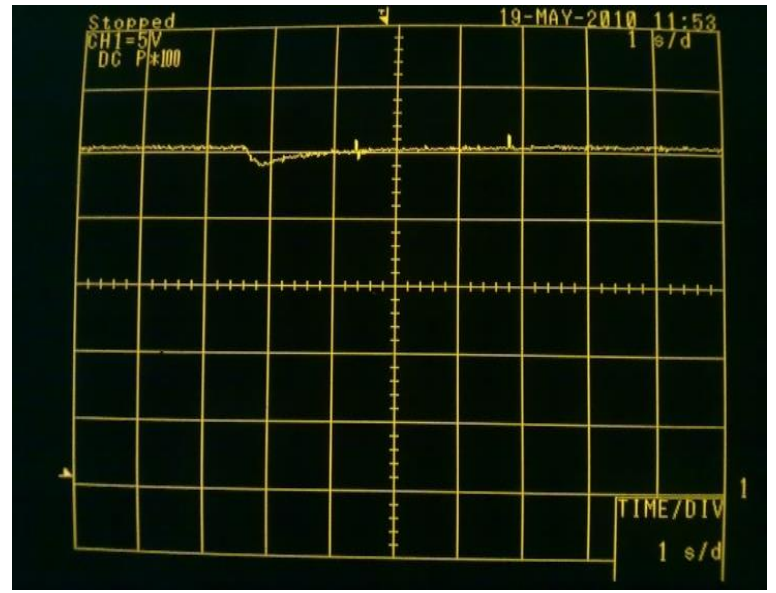

Figure (16-b) Experimental waveform of motor Speed due to negative Change In load torque.

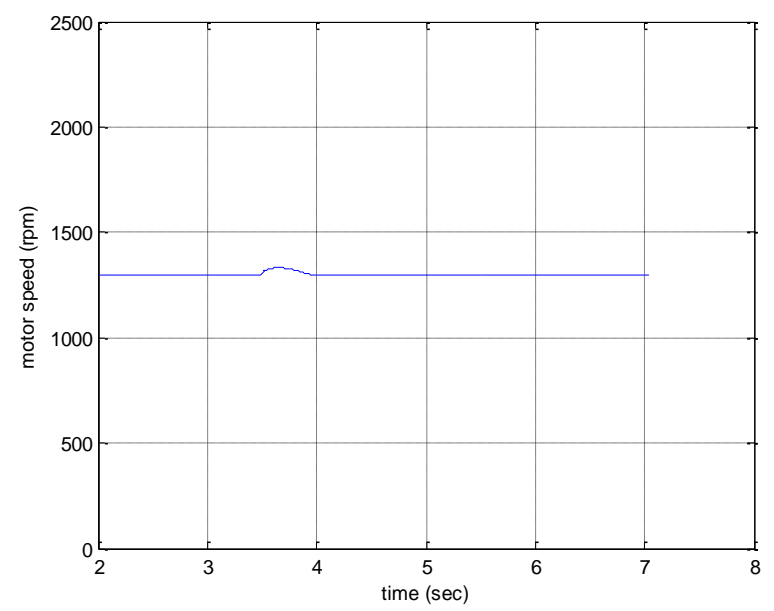

Figure (17-A) Simulation of motor speed in (rpm) Due to positive Change in load torque.

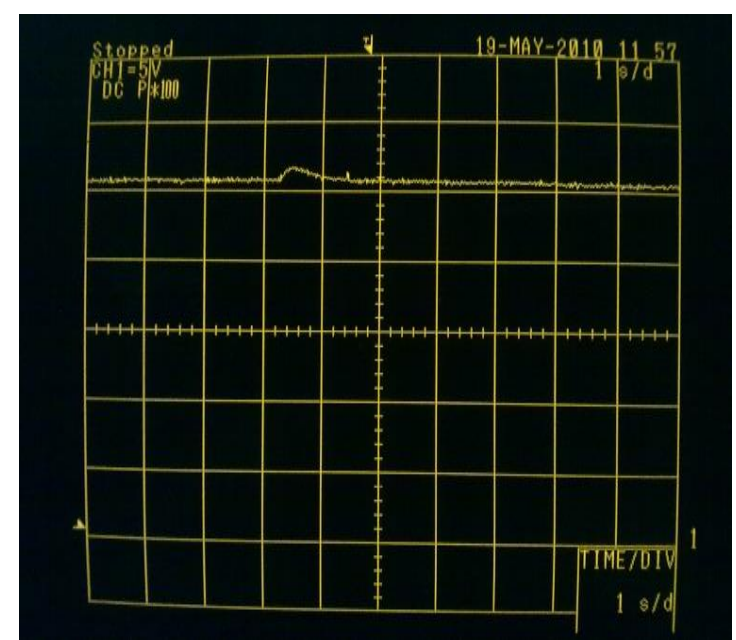

Figure (17-b) Experimental wave form of motor
Speed due to negative Change in load torque.

Figure (18) shows the simulation and experimental results for a positive step change in $\boldsymbol{V}_{\text {ref }}$ from 1300 to 1365 r.p.m. It is observed that the speed can follow the desired reference speed smoothly

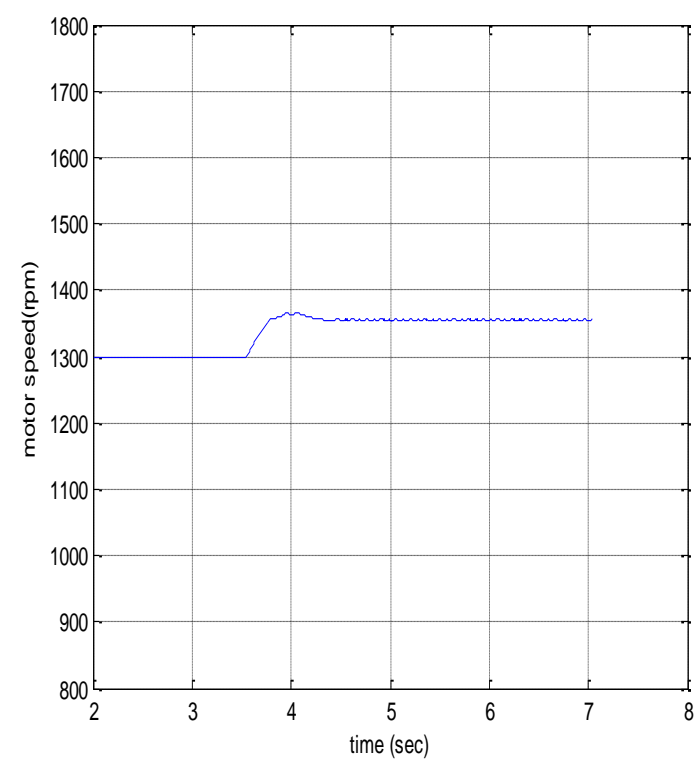

Figure (18-A) Simulation of motor speed in (rpm) due to positive change in reference voltage at full load.

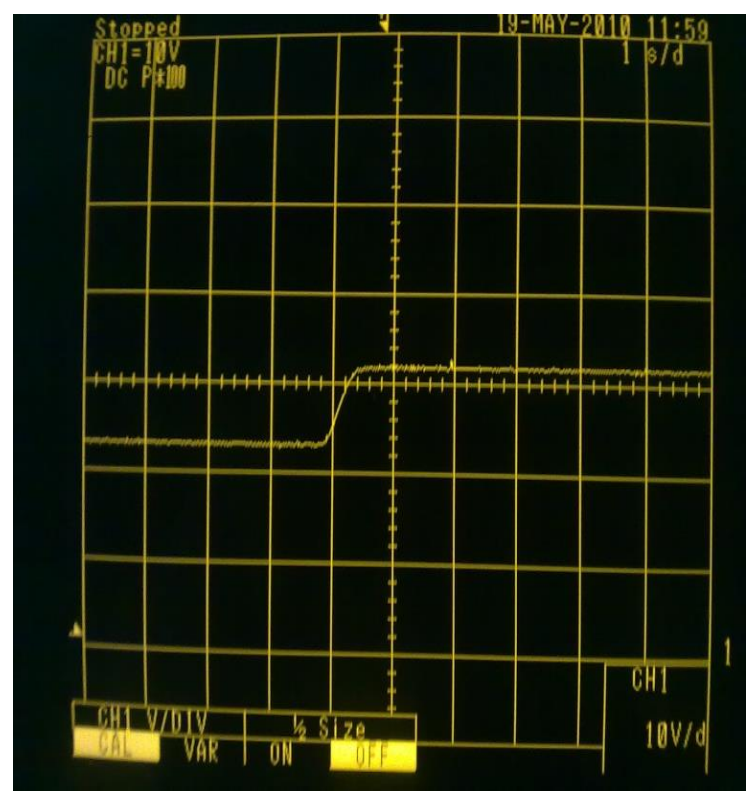

Figure (18-b) Experimental waveform of motor speed due to positive change in reference voltage at full load. 


\section{6- CONCLUSIONS}

This paper presents the modeling simulation and experimental behavior for dynamic and steady state performance of a Cuk AC to DC converter. The use of a Cuk converter achieved the availability to obtaining the step-up and step-down characteristics of the motor input voltage. The presented control circuit for this system is simple since only one switch is used. The obtained Dc motor voltage and current has the advantage to be approximately ripples free. The dynamic and steady state behavior are obtained using the proposed modeling and numerical simulation. The suitable parameters in designing. The proportional integral speed controller are obtained for four zones of load in order to obtain a constant speed when there is a wide range of load change. ALSO, it is found that the motor speed can follow the desired reference speed smoothly .The comparison between the simulation and experimental results for open and closed loop for the speed control have proved that they are in an agreement with each other.

\section{7- REFERENCES}

[1] D.S.L simonetti ,J.sebation and J.uceda , “ the discontinues conduction made sepic and cuk power factor pre-Regulators: Analysis and design ", ,IEEE trans. on Industrial Electronics, vol 44, No5, October ,1997. Pp630-737.

[2] S.S.Shokralla, " A simplified Approach for Closed Loop Speed Control of a DC Motor Using AC-DC converter " Alexandria Engineering Journal, vol. 36, No.2, March 1997 , pp. B29-B41.

[3] R. Itoh and K. Ishizaka, "Single-Phase Sinusoidal Converter Using MOSFET'S", Proc. Inst. Elect. Eng. B. Elect. Power Appl., vol. 136, Sept., pp. 237242, 1989.

[4] M. Kazerani, P.D Ziogas, and G. Joos, " A novel Active Current Wave shaping Technique for Solid-State Input Power Factor Conditioners" ,IEEE Trans. Ind. Electron., vol. 38,Feb. pp.72-78, 1991.
[5] S.Manias, "Novel Full Bridge Semi controlled Switch Mode Rectifier ", Proc. Inst. Elec. Eng.B. Elect. Power Appl., Sept. pp. 252-256, 1991.

[6] A. R. Prasad, P.D. Ziogas, and S. Manias, "An Active Power Factor Correlation Technique for Three-Phase Diode Rectifiers", IEEE Trans. Power Electron, vol.6, Jan. pp. 83-92, 1991.

[7] M. E. El-Shebiny, " Performance Characteristics of a Fly back Converter Fed Dc motor " , Engineering Research ?Journal, vol. 25, No. 1 , January 2002, pp. 1-15.

[8] Rashid, M. H., "Power Electronics, Circuits, DDevices and Applications", Prentice-Hall International, Inc. 1

[9] J.T. boys and A.W. Green, "CurrentForce Single-Phase Reversible Rectifier" ,Proc. Inst. Elec. Eng. B. Elect Power Appl. ,Vol. 136,Sept.pp. 205-211, 1989.

[10] I. Takahashi, et al., "High Power Factor Correction Switiching Regulator with no Rush Current", IEEE Trans. on Industry Applications, Jan. 1992, pp.673-680.

[11] R. Itoh and K. Ishizaka, "Single-Phase Stepup/down Current Source Rectifier With Suppressed Resonance", IEE Proc. B ( Electric Power Applications)), Vol. 141, Jan. 1994, pp. 19-25.

[12] A. Mchi and S. Funabiki, " Step-up/down Voltage PMW AC-to- DC Converter with One Switching Device", IEE proc. B (Electric Power Application), Vol. 140, Jan. 1993, pp. 35- 43.

[13] D.Maksimovic, "Design of ClampedCurrent High-Power-Factor Boost Rectifier", IEEE Trans. on Industry Application,Vol. 31, No. 5, Sept/Oct. 1995, pp. 986-992.

[14] D. Maksimovice, Y. Jang and R. W. Erickson, "Nonlinear-Carrier Control for High Power- Factor Boost Rectifiers", IEEE Trans. on Power Electronics, Vol. 11, No. 4, July 1996. 
[15].M.C. Ghanem,K. Al-Haddad and G. Roy, "A new Control Strategy to Achieve Sinusoidal Line Current in a Cascade BuckBoost Converter",IEEE Trans. on Industrial Electronics,Vol.43,June 1996,pp.441-449.

[16] R.D. Brioschi and J. F. Vieira., "High Power- Factor Electronic Ballast with Constant DC-Link Voltage ", IEEE Trans. on Power Electronics, Vol 13, No.6, Nov.1998,pp.1030-1037.

[17] T.H. Abdelhamid, "Three-Phase PWM DC Drive System with Active Input Power Factor Correction ",Proceedings of sixth Middle

East PowerConference"MEPCON`98", Mansoura, Egypt, Dec. 15-17, 1998,pp.4751.

[18] T. Nabil Tweig, "Closed-Loop Speed Control of A DC Motor Using AC to DC Buck-Boost Converter " , The 9 Internationl MEPCON 2005 Conference, DEC, 13-15, 2005, Port-Said, Egypt.

[19] B.R Lim and T.S Hwang, "Topologies For High Power Factor Three-Phase AC to DC Converter”,EPE`95 Conference, Sevilla, pp. 2858-2863.

[20] A.E Emanuel and K.K Sen, " Steady-State Performance of the DC Motor Supplied From Single-Phase Rectifier With Step-Up Converter A Unity Power Factor Converter " , IEEE Trans. On Energy conversions, Vol. 3, No. 1, March, pp. 172-178, 1988.

[21]S. S. Shokralla and E. E. M. Rashed, "Dynamic Analysis and Speed Control of AC-DC Boost Converter Fed DC Motor Engineering Research Bulletin, Vol.22,No.2, 1999,pp.110-130.

[22] 22 - Sen, P.C.," Thyristor DC drive ",John Wiley \&Sons Inc., New York, 1981.

[23] Ned. Mohan, T.M Undeland, and W.P. robbins,"Power Electronics Convertyers, Applications and Design", John Wiley and Sons. Inc.New York, 1989.

[24] D. Weng and S. Yuvara Jan, "Constant Switching-Frequency AC-DCConverter
Using Second-Harmonic-Injected PWM", IEEE Trans. On Power Electron ., Vol. 11, Jan. pp. 115-121, 1966.

[25] M.A. Ghazy, "A Novel DC/DC Switching Requlator" ,Al-Azhar Eng. Third International Conference, Dec. 18-12, pp. 117- 128, 1993.

1- C.T Pan and T.C Chen, "Modeling and Design of an A C to DC Converter", , IEEE Trans. On Power Electron ., Vol. 8,Oct. pp.501-508, 1993.

\section{8-APPENDIX (1)}

The measured parameters of the designed system are as follows:

L1=159 mH, L2=159 mH, Fs= 2.2 k HZ, V= 12 volt, $\mathrm{R} 1=0.50 \mathrm{hm}, \mathrm{R} 2=0.5 \mathrm{ohm}, \mathrm{Co}=1600 \mu \mathrm{F}$, $\mathrm{C}=5 \mu F$

\section{APPENDIX (2)}

The test motor is a separately excited DC , 55V, $50 \mathrm{~W}, 1 \mathrm{~A}, 3000 \mathrm{rpm}$, having the following measured parameter

$R_{m}=10.5 \Omega, L_{m}=0.06 H_{s} R_{f}=550 \Omega$

$B=0.0001 \mathrm{Nm}(\mathrm{rad} / \mathrm{s}), K_{m}=0.127 \mathrm{~V} /(\mathrm{rad} / \mathrm{s})$

$$
I=0.0012 \mathrm{~kg} \cdot \mathrm{m}^{2}
$$

\section{APPENDIX (3)}

The values of the proportional integral controller parameter for the four zones are as follows:-

\begin{tabular}{|c||c|c||}
\hline Zone(1) & $K_{1}=0.92$ & $\tau_{1}=0.08$ \\
\hline \hline Zone(2) & $K_{1}=0.83$ & $\tau_{1}=0.11$ \\
\hline \hline Zone(3) & $K_{1}=0.74$ & $\tau_{1}=0.16$ \\
\hline \hline Zone(4) & $K_{1}=0.71$ & $\tau_{1}=0.18$ \\
\hline
\end{tabular}

